THE JOURNAL OF NAVIGATION (2016), 69, 468-480. @ C The Royal Institute of Navigation 2016 This is an Open Access article, distributed under the terms of the Creative Commons Attribution licence (http://creativecommons.org/licenses/by/4.0/), which permits unrestricted re-use, distribution, and reproduction in any medium, provided the original work is properly cited.

doi:10.1017/S0373463315000879

\title{
A History of Maritime Radio- Navigation Positioning Systems used in Poland
}

\author{
Cezary Specht, Adam Weintrit and Mariusz Specht \\ (Gdynia Maritime University, Gdynia, Poland) \\ (E-mail: weintrit@am.gdynia.pl)
}

\begin{abstract}
This paper describes the genesis, the principle of operation and characteristics of selected radio-navigation positioning systems, which in addition to terrestrial methods formed a system of navigational marking constituting the primary method for determining the location in the sea areas of Poland in the years 1948-2000, and sometimes even later. The major ones are: maritime circular radiobeacons (RC), Decca-Navigator System (DNS) and Differential GPS (DGPS), as well as solutions forgotten today: AD-2 and SYLEDIS. In this paper, due to its limited volume, the authors have omitted the description of the solutions used by the Polish Navy (RYM, BRAS, JEMIOLUSZKA, TSIKADA) and the global or continental systems (TRANSIT, GPS, GLONASS, OMEGA, EGNOS, LORAN, CONSOL) - described widely in world literature.
\end{abstract}

\section{KEYWORDS}
1. Radio-Navigation.
2. Positioning systems.
3. Decca-Navigator System (DNS).
4. Maritime circular radiobeacons (RC). 5. AD-2 system. 6. SYLEDIS.
7. Differential GPS (DGPS).

Submitted: 21 June 2015. Accepted: 30 October 2015. First published online: 11 January 2016.

1. INTRODUCTION. Navigation is the process of object motion control (Specht, 2007), thus determination of position is its essence. One type of navigation is maritime navigation, which for several thousand years has used terrestrial, and for dozens of years radio-navigation systems, including methods of determining position by satellite. It is believed that the beginning of the development of radio-navigation is the discovery of radio waves and the invention of the radio in 1895 by Alexander Popov (Urbański and Posiła, 1966), which resulted in the emergence and development of equipment and radio-navigation systems. In 1897 Guglielmo Marconi established radio contact for the first time with a ship located approximately $20 \mathrm{~km}$ away, and four years later he sent a message across the Atlantic (from England to Canada) (Hofmann-Wellenhof et al., 2003). The first radio-navigation systems were non-directional (circular) beacons rendering it possible to determine radio location by means of a (physically or electronically) rotating antenna. They were constructed in around 1897 in England (Urbański 
and Posiła, 1966) and used for navigation at sea in 1921 (Januszewski, 2009), although the first radio ship-finding attempts took place in 1903.

During World War II solutions were developed enabling the measurement of: radio location, distances, or their differences. These were the following systems: GEE (United Kingdom, 1942-1970, accuracy of 0.15-1.6 km); CONSOL (Germany, 1940-1991, radio location accuracy of 0.6-7·5); LORAN A (USA, 1943-2000, accuracy of 2-3 km); LORAN C (USA, 1957-today, accuracy of 0.25-0.46 km) (Groves, 2008; Proc, 2014), so that it was possible to draw items on a chart directly. The invention of the transistor in 1948 and its versatile application in radio-navigation in the 1970s led to the emergence of the first radio-navigation systems with a global reach, such as: OMEGA (1971-1997, accuracy of 2-4 km); TRANSIT (1964-1996, accuracy of $0 \cdot 2-0 \cdot 4 \mathrm{~km}$ ); TSIKADA (1978-2003, accuracy of $0 \cdot 1 \mathrm{~km}$ ) (Groves, 2008; Januszewski, 2009). Subsequent years brought solutions from satellite positioning (GPS, GLONASS, BEIDOU, GALILEO) that determined the shape of modern radio-navigation in the world. Throughout the last 100 years radio-navigation systems have evolved from support systems for determining the radio direction, through measuring the distances or their differences enabling accurate positioning within a few hundred metres, to the precise positioning solutions of Global Navigation Satellite Systems (GNSS) (Nitner and Specht, 2012).

In Poland the beginnings of radio-navigation date back to the 1950s when the network of non-directional coast RCs was set up, covering the Polish economic zone. This radiobeacon arrangement provided the possibility to determine the position (to deliver at least two radio measurements simultaneously) at any place. The complex process of calculation and application of the results on the map was significantly improved after the installation (in 1970) off the Swedish coast of the 0A chain of the Decca Navigator System (DNS) (Proc, 2014). It became the primary positioning system for ships (Mark 5 series receivers) and navy ships (Russian Pirs receivers), until the beginning of the 1990s, when the first Global Positioning System (GPS) receivers appeared.

Particularly interesting from a technical point of view, local area radio systems operating on the Polish coast were: the phase location system AD-2 - developed in the 1970s on the waters of the Bay of Gdańsk intended for positioning tankers entering the North Port (Winogradow, 1978) and SYLEDIS - designed for piloting and hydrography of the port complex of Szczecin - Świnoujście (Kopacz et al., 2001). This paper describes those various systems while using a uniform criterion space: a general description, architecture and principle of operation, positioning accuracy, and use of a system in the sea basin of the Republic of Poland (RP).

\section{MARITIME CIRCULAR RADIOBEACONS (RC)}

2.1. General description. Maritime Circular Radiobeacons (RC) were the first method of positioning using radio waves, which provides the possibility of implementing positioning systems with a range of up to $200 \mathrm{NM}$. The first non-directional RC for maritime navigation was set up in New Jersey, USA in 1921 (Januszewski, 2009), starting as early as the 1920s, with the installation of radio direction finders on ships for measuring the radio bearing in the direction of the radiobeacon commenced (Urbański and Posiła, 1966). Radiobeacons were usually located near lighthouses or installed on beacons, light vessels or ocean weather ships (Hydrographic Office of 


\begin{tabular}{lr} 
identification signal repeated 3-6 times & $22 \mathrm{~s}$ \\
continuous signal for radio direction & $25 \mathrm{~s}$ \\
finding & \\
identification signal repeated 1-2 times & $8 \mathrm{~s}$ \\
Silence & total \\
\cline { 2 - 2 } & $60 \mathrm{~s}$ \\
\hline
\end{tabular}

Figure 1. 1-minute program of maritime RC applied before 1 April 1992 (Januszewski, 1997).

$\begin{array}{lr}\text { identification signal repeated 1-2 times } & 13 \mathrm{~s} \\ \text { continuous signal for radio direction finding } & \begin{array}{l}47 \mathrm{~s} \\$\cline { 2 - 2 }\end{array}$\quad \text { total }\end{array}$

Figure 2. 1-minute program of maritime RC applied from 1 April 1992 (Januszewski, 1997).

the Polish Navy, 1971). In 1991 there were approximately 1300 maritime RC that worked within the band $283.5-315 \mathrm{kHz}$ and had a range of 20 to $200 \mathrm{NM}$ (International Telecommunication Union, 1986; Januszewski, 1997). At the end of the twentieth century radio direction finding was abandoned as a method of determining the position of vessels as it has rather low accuracy. Part of the existing infrastructure was used for the transmission of Differential GPS (DGPS) corrections. For example the radiobeacons in Dziwnów and Rozewie currently transmit DGPS corrections (Dziewicki and Specht, 1996).

2.2. Architecture and principle of operation. Radiobeacons emitted non-directional signals, which were then picked up by the directional receiving antenna mounted on the vessel (Jagodziński, 1961). In this way it was possible to determine the vessel observed position that in terrestrial navigation is the intersection of at least two position lines. Such lines could be a radio bearing, i.e. the sum of the actual heading of the ship and the radio course angle included between the axis of symmetry of the fore part of the vessel and the direction from which the radio wave emitted by a given broadcasting radio station reaches the direction-finding antenna. In order to facilitate and speed up the bearing performance, the beacons were often grouped in a so-called "chain". These included from two to six broadcasting radio stations and worked on the same carrier frequencies. Each of them had a separate and distinct modulation frequency and a separate hallmark also referred to as a beacon code (Eucznik and Sochacki, 1981).

RCs broadcast at regular intervals signals corresponding to the so-called "program" of radiobeacons. Using Morse code they emitted an identification signal and a continuous signal. The former allowed the user to identify the radiobeacon code, while the latter allowed them to determine bearing. Until 1992 this program was identical for all radiobeacons and can be seen in Figure 1.

Because the then radio direction finding stations could not correctly determine radio direction in all circumstances, it was decided to modify the maritime radiobeacons program so that the duration of a continuous signal was extended, and the duration of identification signals was reduced (Figure 2). 


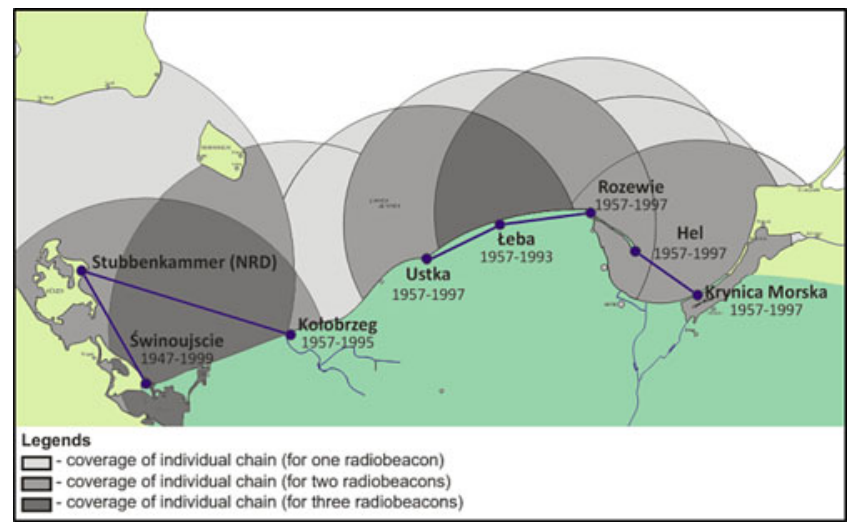

Figure 3. Coverage of individual chains (Hydrographic Office of the Polish Navy, 1971; Łysejko, 2012).

2.3. Positioning accuracy. The error with which the observed position of the vessel was found depended on: the accuracy of the radio bearing, the angle of intersection of these radio bearings, and the distances between the intersection of these radio direction findings from individual radiobeacons (Górski et al., 1990; Weintrit and Specht, 2014). It should be noted that under optimal conditions a radio bearing may be determined with an accuracy of no less than $2^{\circ}$ (Hydrographic Office of the Polish Navy, 1971; National Geospatial-Intelligence Agency, 2005). Also important is the fact that each position line of a bearing, including a radio direction finding bearing, is an orthodromic line, hence the problems with the accuracy in determining the position on a chart in the Mercator projection.

2.4. Maritime radiobeacons ( $R C s$ ) in RP sea basins. In 1970 in the territory of Poland there were seven maritime RC that formed three chains. The first chain, numbered 0003 , included radiobeacons in Krynica Morska $\left(\mathrm{f}=310 \cdot 3 \mathrm{kHz}, \varphi=54 \cdot 23^{\circ} \mathrm{N}\right.$, $\left.\lambda=019 \cdot 27^{\circ} \mathrm{E}, \mathrm{d}=50 \mathrm{NM}\right)$ and $\operatorname{Hel}\left(\mathrm{f}=310 \cdot 3 \mathrm{kHz}, \varphi=54 \cdot 36^{\circ} \mathrm{N}, \lambda=018 \cdot 49^{\circ} \mathrm{E}\right.$, $\mathrm{d}=50 \mathrm{NM})$. The second, numbered 0006 , was formed by radiobeacons in Rozewie $\left(\mathrm{f}=287 \cdot 3 \mathrm{kHz}, \varphi=54 \cdot 50^{\circ} \mathrm{N}, \lambda=018 \cdot 20^{\circ} \mathrm{E}, \mathrm{d}=50 \mathrm{NM}\right)$, Leba $(\mathrm{f}=287 \cdot 3 \mathrm{kHz}$, $\left.\varphi=54 \cdot 46^{\circ} \mathrm{N}, \lambda=017 \cdot 33^{\circ} \mathrm{E}, \mathrm{d}=50 \mathrm{NM}\right)$ and Ustka $\left(\mathrm{f}=287 \cdot 3 \mathrm{kHz}, \varphi=54 \cdot 35^{\circ} \mathrm{N}\right.$, $\left.\lambda=016 \cdot 51^{\circ} \mathrm{E}, \mathrm{d}=50 \mathrm{NM}\right)$. The last chain, numbered 0009 , included radiobeacons in Kołobrzeg $\left(\mathrm{f}=312.6 \mathrm{kHz}, \varphi=54 \cdot 11^{\circ} \mathrm{N}, \lambda=015 \cdot 33^{\circ} \mathrm{E}, \mathrm{d}=60 \mathrm{NM}\right)$, Świnoujście (f $=312.6 \mathrm{kHz}, \varphi=53 \cdot 55^{\circ} \mathrm{N}, \lambda=014 \cdot 17^{\circ} \mathrm{E}, \mathrm{d}=60 \mathrm{NM}$ ) and Stubbenkammer ( $\mathrm{f}=$ $312 \cdot 6 \mathrm{kHz}, \varphi=54 \cdot 34^{\circ} \mathrm{N}, \lambda=013 \cdot 40^{\circ} \mathrm{E}, \mathrm{d}=70 \mathrm{NM}$ ) (Hydrographic Office of the Polish Navy, 1971). See Figure 3.

\section{DECCA-NAVIGATOR SYSTEM (DNS)}

3.1. General description. DNS was a mid-range hyperbolic radio-navigation system, developed by William O'Brien in the years 1936-1939 in the USA. Later, the concept was developed jointly with Harvey Schwarz (Januszewski, 1997; Proc, 2014) in the UK by the Decca Record Company (Blanchard, 2015). Tests, carried out in the Irish Sea 1942-1943, helped to develop technical solutions facilitating the launch of the first chain on the day before the landing of Allied forces in Normandy 


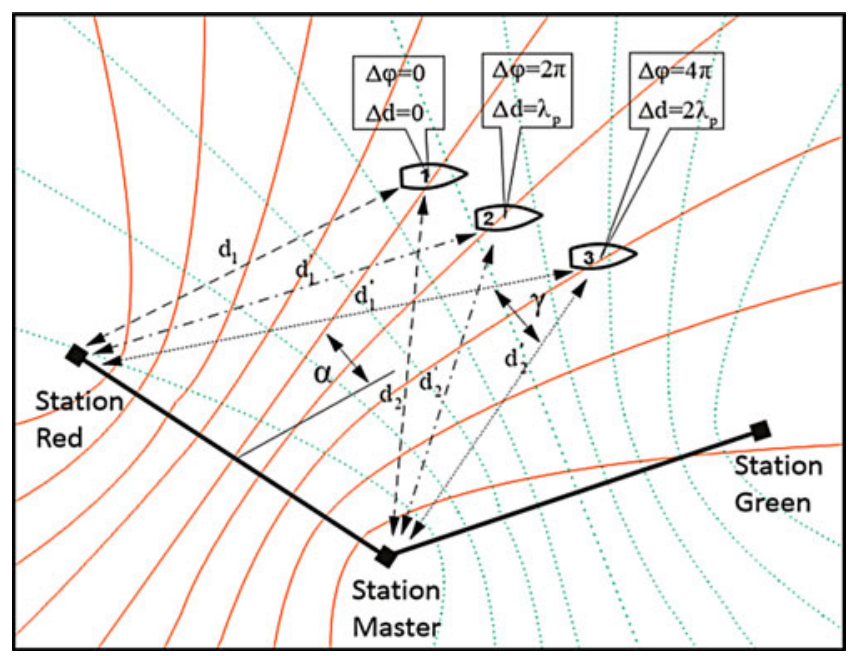

Figure 4. Principle of operation of DNS (Urbański and Posiła, 1966).

in 1944 (a chain of three stations: Chichester - Master A station, Swanage - Slave B station, and Beachy Head - Slave C station) provided the ability to precisely position the Allied fleet (Blanchard, 2015; Proc, 2014).

After World War II Decca Navigator Ltd. was founded, which established the first commercial chain of the system in 1946 in Southern England. Until the 1990s the DNS system was the primary positioning radio-navigation system used in coastal shipping worldwide (Weintrit, 1992). Operational areas included: Eastern Europe, Canada, Japan, South Africa, United Arab Emirates, Bangladesh, Nigeria, India and Australia. At its peak there were 55 chains (Groves, 2008), but by 1996 this had reduced to 30 . The number of receivers used in 1991 was estimated at 225,000 units (Januszewski, 1997). Major Baltic chains were switched off at the end of 1999. The last of the chains (9C, Japan, Hokkaido) worked until March 2001 (Proc, 2014).

3.2. Architecture and principle of operation. The basic element of the system architecture was a chain, consisting of a master station and two or three subordinate stations (usually located at a distance of $80-120 \mathrm{~km}$ from the main station). The principle of operation of the DNS consisted of measuring the phase difference of signals between the master station and the subordinate stations, which in the form of differences in distance were presented on charts in the form of a grid of hyperbolae (Januszewski, 1997; Proc, 2014). The system used broadcast radio signals emitted at frequencies from five ranges: $70 \cdot 087-70 \cdot 583 \mathrm{kHz}, 84 \cdot 105-85.900 \mathrm{kHz}, 112 \cdot 400$ $114 \cdot 533 \mathrm{kHz}, 114 \cdot 943-117 \cdot 397 \mathrm{kHz}, 126 \cdot 157-128 \cdot 850 \mathrm{kHz}$ with a frequency multiple access (Frequency Division Multiple Access) (Proc, 2014). A ship receiver, moving in the zone of an operating system, performed phase difference measurements of radio signals coming from pairs of stations: master and red, and master and green etc. (Figure 4). At position (1) the receiver is on a line perpendicular to the base line (distances to both stations are identical), and the measured phases difference is 0 . At point (2) the phase difference increases by the value of $\Delta \varphi=2 \pi$, hence the difference in distance will increase by the value of the length of a radio wave corresponding to 
the wavelength comparator, in which the measurement of phases difference is performed $\left(\lambda_{p}\right)$. Similarly, at point (3), where $\Delta \varphi=4 \pi$, and the distance difference will be $\Delta d=2 \lambda_{p}$, hence the relationship between the measured phases difference $\Delta \varphi$, and the difference in the distance $\left(d_{1}-d_{2}\right)$ between a pair of stations (master and red, and master and green) can be written down as (Urbański and Posiła, 1966):

$$
\Delta \varphi=2 \pi \frac{\left(d_{1}-d_{2}\right)}{\lambda_{p}}
$$

The ship receiver performed the phase difference measurement with an accuracy of $1^{\circ}$. As the distance from the master base line increased the width of position band grew (d), the accuracy of the measurement decreased as the distance to the master base line increased (between the master and slave stations) (Urbański and Posiła, 1966):

$$
d=2 d_{0} \cdot \frac{\gamma}{b} \cdot \frac{1}{\cos (\alpha)}=\frac{\lambda_{p}}{2 \sin \left(\frac{\gamma}{2}\right)}
$$

Where $d$ is the width of a position band, $d_{0}$ is the width of a position band at the master base line, $\alpha$ is the angle between a symmetric master base line and a direction defined from its intersection on a master base line indicated towards the ship receiver (marked on Figure 4 for point No. 3) and $\gamma$ is the reference angle between rays connecting the ship with master and slave stations (marked at Figure 4 for point No. 3).

3.3. Positioning accuracy. Determination of the position was acceptable in the context of a single chain, because it provided time synchronization of the broadcast, for which the master station was responsible. The primary factors determining the accuracy were: an angle of intersection of the position lines (hyperbolas) used to determine the position, a distance from the station and a time of day affecting the signal propagation conditions (i.e. the troposphere effect). Accordingly, the positioning accuracy ranged from $50 \mathrm{~m}$ during the day to $200 \mathrm{~m}$ at night. For maximum ranges (300-400 NM) it reached a value of up to $800 \mathrm{~m}$.

3.4. Decca-Navigator system in RP sea basins. The Polish economic zone area was covered entirely by the Swedish chain operations 0A - South Baltic (launched in 1970, switched off in 1999) with stations located in Holmsjö (Sweden, master, $\mathrm{f}=$ $84 \cdot 100 \mathrm{kHz}, \varphi=56 \cdot 450^{\circ} \mathrm{N}, \lambda=015 \cdot 667^{\circ} \mathrm{E}$ ), in Sandhammaren (Sweden, slave red, $\mathrm{f}$ $=112 \cdot 133 \mathrm{kHz}, \varphi=55 \cdot 400^{\circ} \mathrm{N}, \lambda=014 \cdot 183^{\circ} \mathrm{E}$ ) and in Burgsvik (Sweden, slave green, $\mathrm{f}=126 \cdot 150 \mathrm{kHz}, \varphi=57 \cdot 017^{\circ} \mathrm{N}, \lambda=018 \cdot 250^{\circ} \mathrm{E}$ ) (Proc, 2014). In the Baltic straits the closest of the available chains was a Swedish chain (4B - North Baltic) and a Danish one (7B - Danish).

\section{AD-2 SYSTEM}

4.1. General description. The AD-2 was a radio-navigation phase location positioning system, which was built by the Institute of Telecommunications of Gdańsk University of Technology (PG). Its main task was to provide navigation cover on the waters of the Bay of Gdańsk, and in particular providing positioning security for ships arriving in the newly constructed North Port in Gdańsk (Kopacz and Urbański, 1989). In 1976 the Maritime Office in Gdynia made its first attempt at implementing the AD-2 system. Over the two years of initial operation the system met technical and operational assumptions posed by the Polish Government 


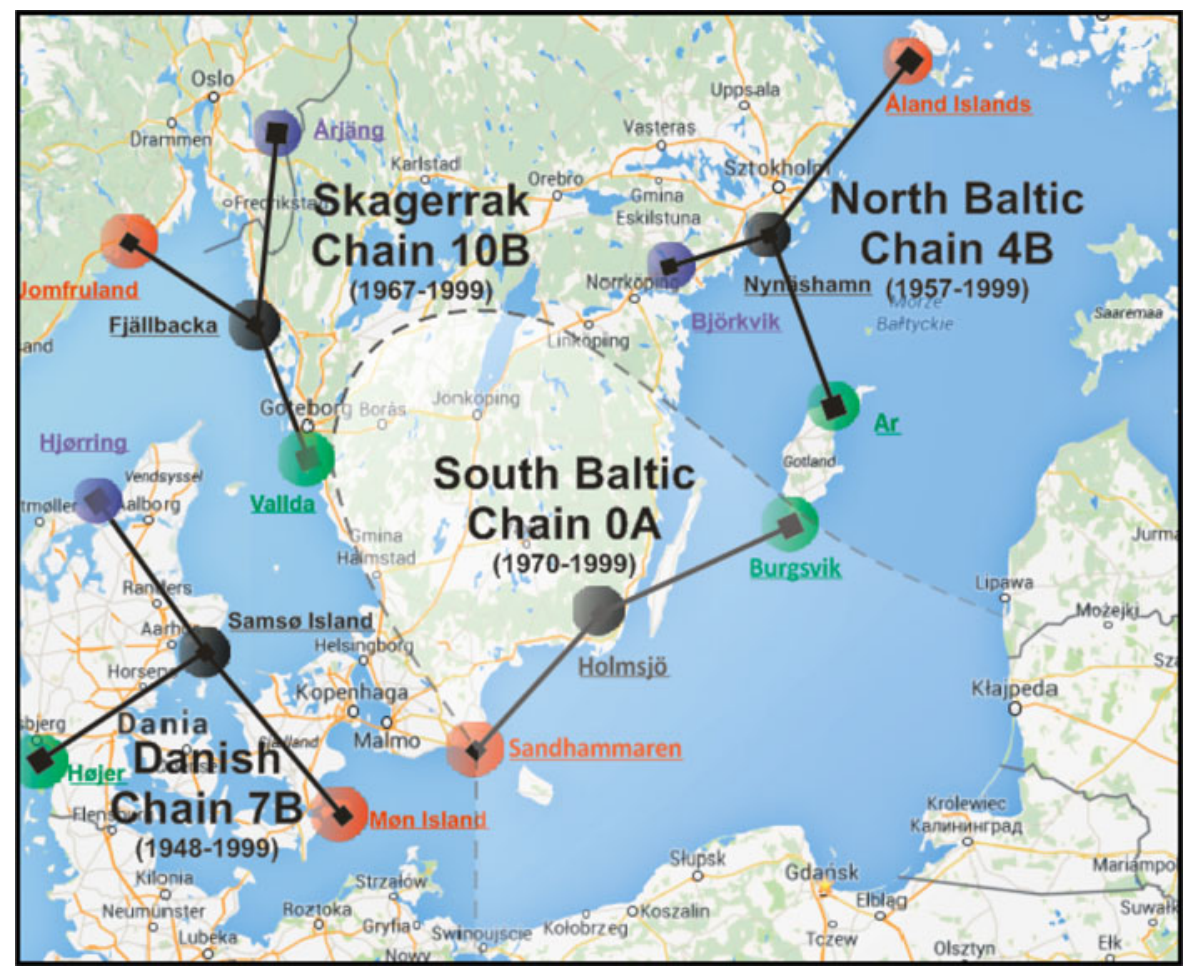

Figure 5. Chains of DNS available in RP sea basins in years 1948-1999 (Proc, 2014).

Institute of Telecommunications, and then it was designated for use (Winogradow, 1978). The AD-2 system worked until 1999, when its broadcasting stations were disassembled (Tomczak-Janowski, 2011). The basic element of the system architecture was a chain, consisting of a master station and three subordinate stations. During the operation of the AD-2 system there was only one chain located on the Bay of Gdansk.

4.2. Architecture and principle of operation. The system consisted of broadcasting stations that emitted synchronous signals at regular intervals at two frequencies $f_{1}$ and $f_{2}\left(f_{1}\right.$ - measurement frequency; $f_{2}$-identification frequency of the hyperbolic band) being, respectively: $1920 \mathrm{kHz}$ and $1728 \mathrm{kHz}$ (Januszewski, 1984). On the basis of the measured phase difference of signals of the station on the ship receiver indicator there was displayed the number of the hyperbolic belt. The selected two pairs of broadcasting stations (Figure 6) (D-B, D-C and D-A, D-B) were drawn on navigation charts as corresponding hyperbolic grids. By reading the relevant hyperbolic belts the navigator could determine the observed position of the vessel, at the intersection of the two selected hyperboles (position lines). It should be noted that the AD-2 system receivers were able to connect to a minicomputer which could then convert the hyperbolic coordinates into geographical ones (Tomczak-Janowski, 2011).

4.3. Positioning accuracy. The selection of frequencies $f_{1}$ and $f_{2}$ increased the width of the hyperbolic belt compared with the width corresponding to the frequency $f_{1}$ in relation $f_{1} /\left(f_{1}-f_{2}\right)=10$. This allowed broadcasting stations to provide the opportunity to determine the position at a range up to $100 \mathrm{NM}$. The instrumental accuracy 

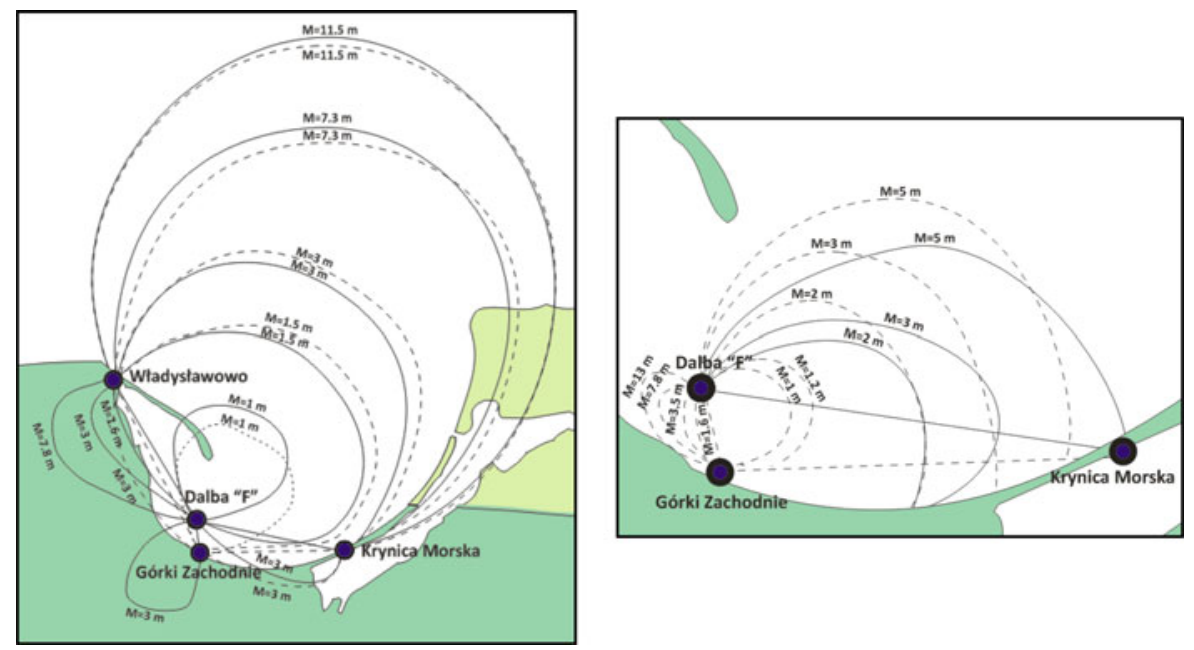

Figure 6. Accuracy zones for two variants of pairs of stations for AD-2 system (Winogradow, 1978).

for determination of a positional line was equal to $0 \cdot 01$ of the width of the position (reference) belt. In the vicinity of the reference base line connecting the various stations, the accuracy of the system was less than $1 \mathrm{~m}$ (Januszewski, 1984; Januszewski and Szymoński, 1982). Figure 6 presents the accuracy zones for two pairs of broadcasting stations (D-B, D-C and D-A, D-B) of the AD-2 system.

4.4. AD-2 system in RP sea basins. The AD-2 consisted of a master station (D) located in Górki Zachodnie and subordinate stations: a dolphin or artificial islet "F" located on the waters of the Bay of Gdańsk (station A), in Krynica Morska (station B) and Władysławowo (station C). In 1985 floe and ice caused flexion of the base of dolphin "F". Station A was so damaged that the authorities decided to blow it up. From that moment the AD-2 chain in the Bay of Gdańsk worked with three broadcasting stations, until 1999 (Tomczak-Janowski, 2011).

\section{SYLEDIS SYSTEM}

5.1. General description. The SYLEDIS system (SYstem LEger por mesure la DIStance) was a terrestrial, radio-navigation positioning system operating in the Ultra High Frequency (UHF) frequency range including: $408-434 \mathrm{MHz}$ and 420 $450 \mathrm{MHz}$. SYLEDIS was a medium-range system, and its operational zone covered $80-120 \mathrm{~km}$ from the reference station. It was implemented for use in the early $1980 \mathrm{~s}$. The manufacturer was the French company Sercel S.A. It was intended for positioning oil extraction activities in the North Sea, where several chains of this system were set up (Loweth, 1997). In 1999, it was activated on the waters of the Pomeranian Bay as a back-up (to the DGPS system) with an objective to ensure precise positioning of piloting activities of the port complex of Szczecin - Świnoujście and to deliver hydrographic work.

5.2. Architecture and principle of operation. The SYLEDIS system works on the basis of chains consisting of several stations. Depending on need the chain can be 

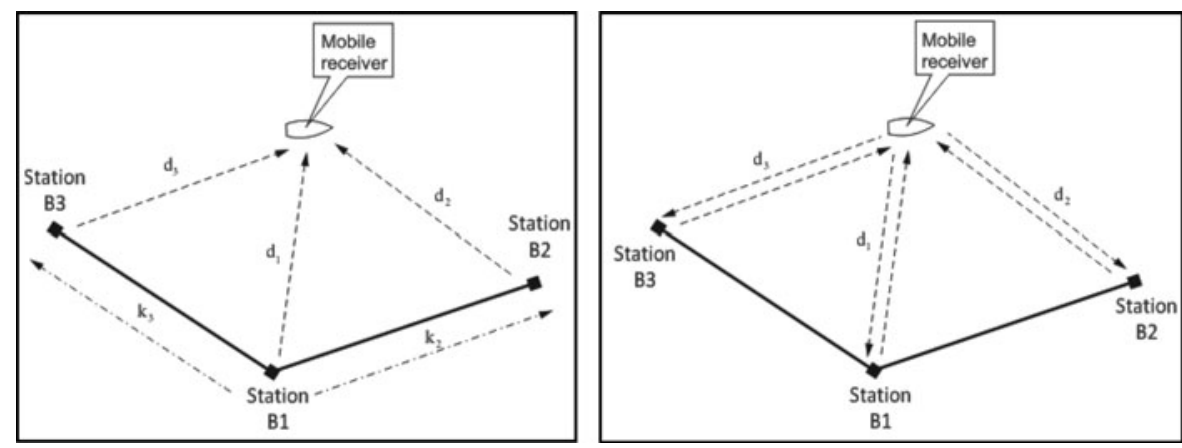

Figure 7. Principle of operation of the SYLEDIS system: in a passive (left) and in an active mode (right) (Sercel S. A., 1981).

configured in a passive mode (control of the operation is carried out from one of the stations - called the master station) or an active mode in which the ship's receiver controls the work. The system uses measurement of the distances between the receiver and stations, or their differences. For this purpose, pseudo-random binary codes of 127 bits are used, that are generated using 7 bit shift registers with feedback. The broadcasting time of a single bit is $0.52 \mu \mathrm{s}$, and a code period is $66.6 \mu \mathrm{s}$. The system operates in chains whose central frequency is selected from the range $408-448 \mathrm{MHz}$ in steps of $2 \cdot 5 \mathrm{kHz}$ or $5 \mathrm{kHz}$, with a $2.5 \mathrm{MHz}$ bandwidth ( $99 \%$ power). The distance measurement accuracy is higher than $0.5 \mathrm{~m}$, ensuring the accuracy in position determination from 1 to $10 \mathrm{~m}$ beyond the range border (the radio horizon). In a passive mode (pseudorange) the broadcasting stations are temporally synchronized. One of them is the master station (Figure 7, station B1) transmitting signals to other stations and the receiver. The subordinate stations - slaves (Figure 7, stations B2 and B3) retransmit the received signals from the master station to the user (Sercel S. A., 1981).

$$
\begin{gathered}
d_{1}=D_{1}+D_{0}=\sqrt{\left(X-X_{1}\right)^{2}+\left(Y-Y_{1}\right)^{2}}+D_{0} \\
d_{2}=D_{2}+D_{0}+d_{12}=\sqrt{\left(X-X_{2}\right)^{2}+\left(Y-Y_{2}\right)^{2}}+D_{0}+k_{1} \\
d_{3}=D_{3}+D_{0}+d_{13}=\sqrt{\left(X-X_{3}\right)^{2}+\left(Y-Y_{3}\right)^{2}}+D_{0}+k_{2}
\end{gathered}
$$

where $d_{1}, d_{2}, d_{3}$ are the measured distances between a receiver and a broadcasting station, $\left(X_{1}, Y_{1}\right),\left(X_{2}, Y_{2}\right),\left(X_{3}, Y_{3}\right)$ are the coordinates of the SYLEDIS system stations, $(X, Y)$ are the coordinates of the SYLEDIS system receiver, $D_{0}$ is the clock fault towards the master station, $D_{1}, D_{2}, D_{3}$ - real distances between stations and a receiver and $k_{1}, k_{2}$ are the length of reference lines between the master and slave stations.

In active mode the ship's station performs system control by sending radio signals to (shore) stations to determine the distances to more accurately determine position (Sercel S. A., 1981).

5.3. Positioning accuracy. The system worked at a very short wavelength of $70 \mathrm{~cm}$. For this reason, the positional line designation error was $0.5 \mathrm{~m}$ (RMS) and up, while ensuring a good station geometry (Bakker et al., 1989). Beyond the reach of the radio 
horizon the error grew within the range of 5-10 $\mathrm{m}$. The manufacturer of the system offered antennae whose directivity characteristics could be arbitrarily adjusted, hence it was possible to obtain a range of up to more than $100 \mathrm{~km}$ from the station. But with this solution the precision of the position determination already reached tens of metres.

5.4. SYLEDIS system in RP sea basins. In 1999 in the waters of the Pomeranian Bay the SYLEDIS radio-navigation system was implemented. The architecture of this system consisted of shore stations which were located so as to be able to efficiently change the chain operation variant (passive or active). The chain of the SYLEDIS system operating in an active mode consisted of stations located on: lighthouses in Niechorze, Świnoujście and Greifswalder Oie, the tower of the harbour master's office in Świnoujście and the hydrographic survey ship "Planet" (a mobile station). The chain operating in a passive mode used almost identical stations as in the active mode (instead of the mobile station they used the border leading light in Świnoujście). In 2001 dynamic measurements were carried out, which helped to determine the accuracy of the SYLEDIS system. The differences between the positions measured by the SYLEDIS system and the positions adopted as model ones (geodesically measured) amounted to $5 \cdot 7 \mathrm{~m}(\mathrm{p}=0 \cdot 95)$ (Kopacz et al., 2001).

The SYLEDIS system, due to the lack of ship's receivers and because of the DGPS system already working on the waters of the Pomeranian Bay operating on the basis of the reference station Dziwnów was not practically applied by users at sea. The dismantled broadcasting stations of the system along with the receivers are at the disposal of the Maritime Office in Szczecin. It is interesting that in 2014 the maritime administration listed the SYLEDIS system as a system being a part of the infrastructure providing access to the Ports of Świnoujście and Szczecin.

\section{DIFFERENTIAL GPS (DGPS)}

6.1. General description. Differential GPS (DGPS) is a positioning system that transmits positional pseudorange GPS fixes/corrections (determined at the reference DGPS station) to maritime users, allowing positioning with accuracies significantly exceeding autonomous GPS positioning. It is designed to protect coastal waters navigation, entrances to ports and hydrography. In terms of radio use it applies a frequency range of $283.5-325 \mathrm{kHz}$ and Minimum Shift Keying (MSK) technique modulated signals. In 1989 the first test of the DGPS system based on the Low Frequency/ Medium Frequency (LF/MF) band and a maritime radiobeacon Montauk Point located on Long Island (USA) was conducted, and on 15 August 1990 it began its continuous operation as the world's first public access DGPS. In the 1990s it was common to locate such stations in most coastal waters of the world. Until 2013 there were 283 DGPS reference stations erected, including two Polish ones: Rozewie and Dziwnów (1994) (Kopacz and Specht, 2014; Specht, 2007).

6.2. Architecture and principle of operation. The Polish DGPS system consists of two DGPS reference stations located in Rozewie and Dziwnów, the central station in Gdynia whose task is to remotely control the reference stations and to supervise the entire system. Until 2009 the Polish DGPS system also included monitoring stations (Kopacz and Specht, 2014) (located in the same place as the reference stations), whose task was to control the system operation parameters in real time. The idea of the system is to determine the measurement error of the measured pseudorange to 


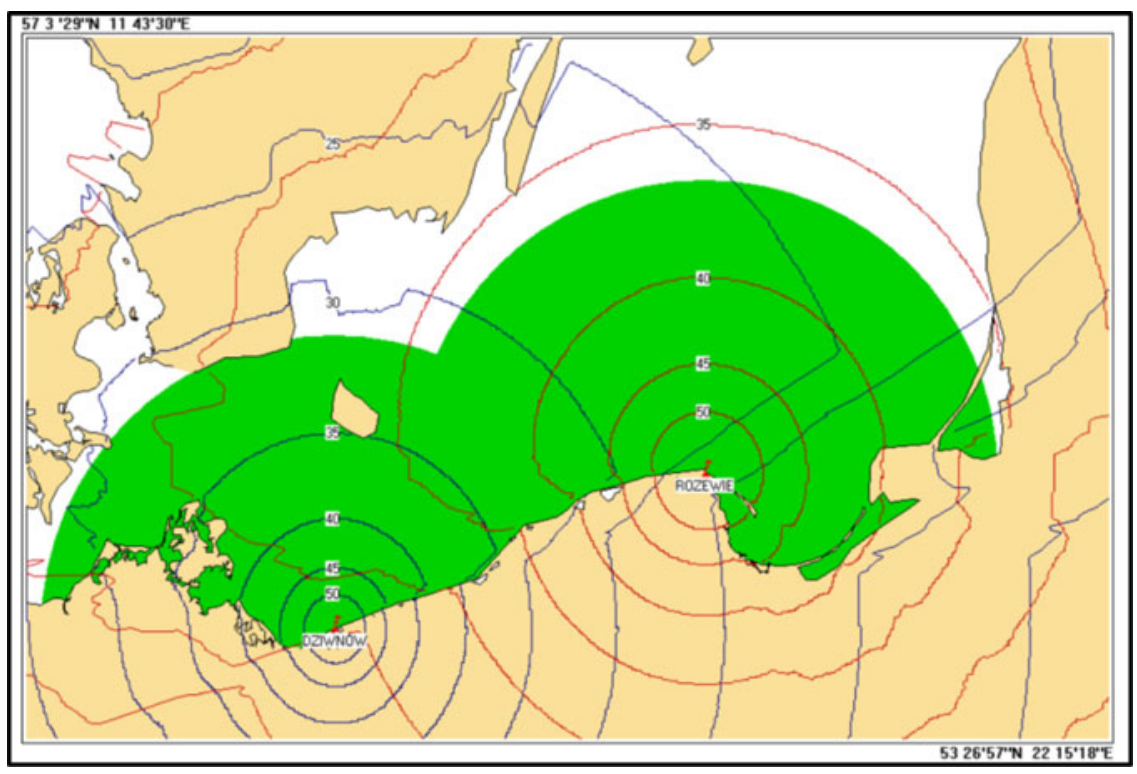

Figure 8. Coverage of Polish DGPS reference stations in 2014 (Śniegocki et al., 2014).

the GPS satellites, and to compare it with the actual distance calculated based on the GPS coordinates of the reference station antennas and the satellite coordinates. Their difference, called the pseudorange correction/fix, is transmitted in the frequency range of $283 \cdot 5-325 \mathrm{kHz}$ to maritime users, who by using the DGPS receiver take it into account in the process of determing position. The reference station consists of a computer, two GPS receivers, two modulators, two amplifiers and a broadcasting antenna. Doubling of devices provides the ability to achieve high availability of signals (Specht, 2007).

6.3. Positioning accuracy. The main factor that decided the accuracy of position was selective availability, namely the technique of intentionally lowering the accuracy of GPS applied by the US government until 2 May 2000 (Specht, 2007). After it had been disabled, the positioning accuracy of the DGPS system increased from the level of 5-10 $\mathrm{m}$ to 1-2 $\mathrm{m}$ (Śniegocki et al., 2014). Currently, the positioning accuracy is essentially dependent on the age of pseudorange corrections received by the user of the system. Age of corrections is the time that has elapsed since their establishment on a DGPS reference station until they were included in the receiver in the process of determining the position. DGPS systems use transmission speeds of 100 and 200 bauds. The average age of corrections is approximately $7 \mathrm{~s}$ and for the latter around $3 \mathrm{~s}$ respectively. Another factor affecting the accuracy is the distance between the reference station and the user.

6.4. DGPS system in RP sea basins. In February 1994, initiated by the Polish Hydrographic Office there was developed "The Concept of Maritime Radiobeacons Location on the Polish Coast", primarily concerning the modernisation of the Polish system of maritime radiobeacons, which also presents the five distribution variants for DGPS reference stations on the Polish coast. It was implemented by the Else 
Technical and Research Service Co. Ltd., from Gdańsk (Else Technical and Research Service Co. Ltd., 1994). Simultaneously, the Polish Hydrographic Office commissioned the Polish Naval Academy to draw on scientific expertise including assumptions for the implementation of this project. A study entitled "Criteria for the Selection of DGPS Reference Station on the Polish Coast" was carried out in the Institute of Navigation and Sea Hydrography of the Polish Naval Academy (Kopacz et al., 1994) on the basis of a commission from the Polish Hydrographic Office No. BHRP-1058/94 of 19.10.1994. In the years 1994-1995 the system was subjected to thorough testing of position accuracy, availability, reliability and credibility, to finally start the operating mode in 1996. Over the years both stations had transmitting antennae exchanged, as well as their other equipment (2009). The range of both stations is around $200 \mathrm{~km}$. Figure 8 illustrates the coverage of Polish reference stations (Rozewie and Dziwnów) defined by measurement in 2014 (Śniegocki et al., 2014).

7. CONCLUSIONS. In this paper the authors describe the history of maritime radio-navigation positioning systems used in Poland. The authors confined themselves to the description of the main systems used in the sea areas of the Republic of Poland in the years 1948-2015. Due to the volume of the publication they omitted systems used by the Polish Navy.

When analysing the development of maritime positioning techniques applying radio waves it should be noted that, over the years, not only were the latest worldwide solutions available used, but also a proprietary and generic system of positional radiolocation has been developed (AD-2); also, the SYLEDIS precise navigation system was implemented to work in the Pomeranian Bay; moreover, Poland was one of the first countries in the world to launch a national DGPS network, which is still operating today.

\section{REFERENCES}

Bakker, G., De Munck, J. C. and Strang van Hees, G. L. (1989). Radio Positioning at Sea: Geodetic Survey Computations, Least Squares Adjustment. Delft University Press.

Blanchard, W. (2015). The Genesis of the Decca Navigator System. The Journal of Navigation, 69(2), 219-237.

Dziewicki, M. and Specht, C. (1996). DGPS Systems in the South Baltic. Proceedings of the Navigation Safety, Gdynia (in Polish).

Else Technical and Research Service Co. Ltd. (1994). The Concept of Maritime Radiobeacons Location on the Polish Coast (in Polish).

Górski, S., Jackowski, K. and Urbański, J. (1990). Evaluation of the Navigation Process Accuracy. Gdynia Maritime Academy Publishing House (in Polish).

Groves, P. D. (2008). Principle of GNSS, Inertial and Multisensor Integrated Navigation Systems. Artech House.

Hofmann-Wellenhof, B., Legat, K. and Wieser, M. (2003). Navigation: Principles of Positioning and Guidance. Springer-Verlag.

Hydrographic Office of the Polish Navy. (1971). Admiralty List of Radio Signals, IV (in Polish).

International Telecommunication Union. (1986). Final Acts of the Regional Administrative Conference for the Planning of the Maritime Radio-Navigation Service (Radiobeacons) in the European Maritime Area.

Jagodziński, Z. (1961). Radio-Navigation Systems. National Defence University Publishing House (in Polish).

Januszewski, J. (1984). High Accuracy Radio-Navigation Systems. Gdynia Maritime Academy Publishing House (in Polish). 
Januszewski, J. (1997). Terrestrial Radio-Navigation Systems. Gdynia Maritime Academy Publishing House (in Polish).

Januszewski, J. (2009). Terrestrial and Satellite Radio-Navigation Systems Yesterday, Today, Tomorrow. Telecommunications Review and Telecommunications Messages, 1, 11-15 (in Polish).

Januszewski, J. and Szymoński, M. (1982). Hyperbolic Systems in Maritime Navigation. Maritime Publishing House (in Polish).

Kopacz, Z., Dziewicki, M., Fic, Z. and Specht, C. (1994). Criteria for the Selection of DGPS Reference Station on the Polish Coast. Polish Naval Academy Publishing House (in Polish).

Kopacz, Z., Morgaś, W., Pawłowski, P. et al. (2001). Modernization of the SYLEDIS Radio-Navigation System in the Pomeranian Bay. Research Project under the Code Name „SYLEDIS-3” (in Polish).

Kopacz, Z. and Specht, C. (2014). Polish DGPS System - Origin: 1991-1993. Scientific Journal of Polish Naval Academy, 2(197), 73-98.

Kopacz, Z. and Urbański, J. (1989). Radio-Navigation Systems Applications in Maritime Hydrography. Polish Naval Academy Publishing House, Part A (in Polish).

Loweth, R. P. (1997). Manual of Offshore Surveying for Geoscientists and Engineers. Chapman \& Hall.

Łucznik, M. and Sochacki, Z. (1981). Radio Direction Finding in Maritime Navigation. Maritime Publishing House (Nautics Library) (in Polish).

Łysejko, A. (2012). Polish Lighthouses. ZET Publishing House (in Polish).

National Geospatial-Intelligence Agency. (2005). Radio Navigational Aids. Springfield, 117.

Nitner, H. and Specht, C. (2012). Radio-Navigation Systems - Definitions and Classifications. Hydrographic Review, 7, 1-13 (in Polish).

Proc, J. (2014). Hyperbolic Radio-Navigation Systems. http://www.jproc.ca/hyperbolic/index.html. Accessed 28 April 2015.

Sercel, S.A. (1981). SR3 Installation-Operation. Edition October 1981.

Specht, C. (2007). GPS System. Bernardinum Publishing House (in Polish).

Śniegocki, H., Specht, C. and Specht, M. (2014). Testing Accuracy of Maritime DGPS System Based on Long-Term Measurements Campaigns over the Years 2006-2014. International Journal of Civil Engineering and Technology, 5(10), 1-8.

Tomczak-Janowski, J. (2011). AD-2 Hyperbolic System. http://heading.pata.pl/hipsad2.htm. Accessed 28 April 2015 (in Polish).

Urbański, J. and Posiła, J. (1966). Radio-Navigation. Polish Naval Academy Publishing House (in Polish).

Weintrit, A. (1992). Maritime Navigation MNS $2000 \mathrm{G}$ System of Racal Decca. Proceedings of the $8^{\text {th }}$ Scientific and Technical Conference „, The Role of Navigation in Support of Human Activity on the Sea”, Gdynia (in Polish).

Weintrit, A. and Specht, C. (2014). Selected Meteorological Issues in Maritime Navigation, in book: Selected Issues of Mobile Measurement Systems. Military University of Technology Publishing House, 123-167 (in Polish).

Winogradow, A. (1978). Securing the Radio-Navigation of the Bay of Gdansk with the AD-2 Hyperbolic System, in book: Problems of Maritime Geodesy and Navigation Safety. Materials for the $4^{\text {th }}$ Symposium of the Institute of Navigation and Hydrography of the Polish Naval Academy, 2444 (in Polish). 